\title{
Hepatic Transcript Profiles of Cytochrome P450 Genes Predict Sex Differences in Drug Metabolism ${ }^{\mathbb{S}}$
}

\author{
James C. Fuscoe, Vikrant Vijay, Joseph P. Hanig, Tao Han, Lijun Ren, James J. Greenhaw, \\ Richard D. Beger, Lisa M. Pence, and Qiang Shi
}

Division of Systems Biology, National Center for Toxicological Research, US Food and Drug Administration, Jefferson, Arkansas (J.C.F., V.V., T.H., L.R., J.J.G., R.D.B., L.M.P., Q.S.); and Center for Drug Evaluation and Research, US Food and Drug Administration, Silver Spring, Maryland (J.P.H.)

Received September 17, 2019; accepted February 21, 2020

\begin{abstract}
Safety assessments of new drug candidates are an important part of the drug development and approval process. Often, possible sexassociated susceptibilities are not adequately addressed, and better assessment tools are needed. We hypothesized that hepatic transcript profiles of cytochrome P450 (P450) enzymes can be used to predict sex-associated differences in drug metabolism and possible adverse events. Comprehensive hepatic transcript profiles were generated for F344 rats of both sexes at nine ages, from 2 weeks (preweaning) to 104 weeks (elderly). Large differences in the transcript profiles of 29 drug metabolizing enzymes and transporters were found between adult males and females (8-52 weeks). Using the PharmaPendium data base, 41 drugs were found to be metabolized by one or two P450 enzymes encoded by sexually dimorphic mRNAs and thus were candidates for evaluation of possible sexually dimorphic metabolism and/or toxicities. Suspension cultures of primary hepatocytes from three male and three female adult rats (10-13 weeks old) were
\end{abstract}

used to evaluate the metabolism of 11 drugs predicted to have sexually dimorphic metabolism. The pharmacokinetics of the drug or its metabolite was analyzed by liquid chromatography/tandem mass spectrometry using multiple reaction monitoring. Of those drugs with adequate metabolism, the predicted significant sex-different metabolism was found for six of seven drugs, with half-lives $37 \%-400 \%$ longer in female hepatocytes than in male hepatocytes. Thus, in this rat model, transcript profiles may allow identification of potential sex-related differences in drug metabolism.

\section{SIGNIFICANCE STATEMENT}

The present study showed that sex-different expression of genes coding for drug metabolizing enzymes, specifically cytochrome P450s, could be used to predict sex-different drug metabolism and, thus, provide a new tool for protecting susceptible subpopulations from possible adverse drug events.

\section{Introduction}

Preclinical safety assessments are a crucial step in assuring the development of safe and effective medical products. Despite large investments of resources in this process, drugs can still enter the market with safety liabilities that result in patient injury and even death (Moore et al., 2007). An analysis of the success rate of drugs at phase III clinical trials and at submission to the US Food and Drug Administration (FDA) has shown a decline to about $50 \%$ in recent years. Of 83 phase III and submission failures between 2007 and $2010,66 \%$ were efficacy related,

This work was supported by the intramural research program of the Food and Drug Administration's National Center for Toxicological Research and the Food and Drug Administration's Office of Women's Health [E0755511]. The findings and conclusions in this report are those of the authors and do not necessarily represent the views of the US Food and Drug Administration.

This work was previously presented as a poster presentation at the following meeting: Fuscoe JC, Shi Q, Han T, Ren L, Greenhaw JJ, Hanig J, Beger RD, Pence LM, Schnackenberg LK, Schmitt TC, Desai VG, Moland CL, and Vijay V (2018) Can transcriptomic profiles be used to predict sex-specific drug metabolism? Twelfth Annual Meeting of the Organization for the Study of Sex Differences; 2018 Apr 30-May 3; Atlanta, GA.

https://doi.org/10.1124/dmd.119.089367.

S This article has supplemental material available at dmd.aspetjournals.org. but a substantial portion (21\%) was due to safety issues (Arrowsmith, 2011). Thus, even with extensive preclinical testing and computational approaches, there is a need for better prediction of drug safety in humans.

Preclinical drug assessments may also benefit from consideration of sex as a biologic variable. For example, the US General Accounting Office reviewed ten prescription drugs withdrawn from the market between 1997 and 2000 for safety reasons (www.gao.gov/new.items/ d01286r.pdf). The adverse events associated with the withdrawal of eight of these drugs appeared to present a greater risk for women, suggesting inadequate understanding of sex-related differences. In fact, despite growing recognition for the need to include both sexes in drug evaluation (http://grants.nih.gov/grants/guide/notice-files/not94-100.html; http://grants1.nih.gov/grants/funding/women_min/guidelines_amended_ 10_2001.htm; Institute of Medicine, 2010), sex bias in preclinical research is a continuing problem, with single-sex studies of male animals outnumbering those of females by substantial margins (Zucker and Beery, 2010; Beery and Zucker, 2011). In 2013, the FDA approved a label change for the sleeping aid medication zolpidem tartrate because women were found to be more susceptible to next-day impairment (http:// www.fda.gov/downloads/Drugs/DrugSafety/UCM335007.pdf), possibly by differences in pharmacokinetics or pharmacodynamics (Greenblatt et al., 2004). This marked the first time that FDA had recommended different dosing for men and women for a drug that was intended for both

ABBREVIATIONS: DMET, drug metabolizing enzyme and transporter; FDA, US Food and Drug Administration; LDH, lactate dehydrogenase; NCBI, National Center for Biotechnology Information; P450, cytochrome P450; qPCR, quantitative polymerase chain reaction; $t_{1 / 2}$, half-life. 
sexes. Thus, there is a clear need to consider possible sex differences from the beginning of the drug development process, including preclinical studies. The National Institutes of Health are encouraging such studies by requiring research plans that balance male and female animals and cells in preclinical studies (Clayton and Collins, 2014).

Sex differences in the pharmacokinetics and pharmacodynamics of pharmaceutical drugs have recently been reviewed (Soldin and Mattison, 2009; Waxman and Holloway, 2009; Soldin et al., 2011) and show that men and women may differ in how the body handles a specific drug. Much of the data on sex differences, however, are obtained by post hoc analysis so that firm conclusions are often difficult to draw. The inclusion of explicit sex-difference analysis in future clinical and preclinical studies will be essential for the optimal safe and effective use of medical products for men and women.

To address the knowledge gap that exists for determining possible sex differences during drug development, we hypothesized that hepatic transcript profiles of cytochrome $\mathrm{P} 450$ (P450) enzymes could be used to predict sex-associated differences in drug metabolism. We tested this hypothesis in a rat model system because of the availability of extensive hepatic transcript data (Kwekel et al., 2010; Yu et al., 2014) to make predictions and primary hepatocyte culture techniques for testing the predictions. In previous studies (Kwekel et al., 2010, 2013a,b; Yu et al., 2014), notable sex and age differences in the expression of genes in the liver, kidney, and nine other tissues in normal rats, including genes crucial to drug metabolism, were found. Dramatic differences in gene expression were found between male and female rats, including the rat orthologs to human enzymes CYP1A2, CYP2D6, CYP2C9, CYP2E1, and CYP3A4. Collectively, the enzymes encoded by these genes are responsible for the metabolism of approximately $75 \%$ of all prescribed drugs (Zanger and Schwab, 2013). The functional capacity of drug metabolizing pathways is proportional to the expression levels of individual proteins or enzymes contained within those pathways. Although measurement of individual enzyme activities is a challenging task, measurement of the expression level of genes coding for these enzymes can be done in a relatively straightforward manner by microarray or RNA sequencing analysis. Although gene expression would be an indirect measure of enzyme activity, if differences exist in the expression of these genes between males and females, the functional capacity of these drug metabolizing pathways may vary as well, potentially producing differences in the drug's efficacy or toxicity. In this study, sex-different expression of hepatic transcripts coding for P450 enzymes were identified in rat, along with their target drugs, and the predicted sex difference in drug metabolism was tested in male and female rat primary hepatocytes. Results suggest that hepatic transcript profiles may allow insights into possible sex differences in drug metabolism.

\section{Materials and Methods}

Development of a Comprehensive List of Genes Encoding Drug Metabolizing Enzymes and Transporters Along with Their Drug Substrates. As a first step for this study, a comprehensive list of drug metabolizing enzymes and transporters (DMETs) was needed so that we could examine their expression in rat liver. To our knowledge, there is no resource in which we can find a comprehensive list of DMETs. A list of DMETs and substrate drugs was obtained from the "metabolizing enzymes and transporter data" module of PharmaPendium (Elsevier, Amsterdam, Netherlands). PharmaPendium is a commercial product, which provides comprehensive access to searchable regulatory documents from the FDA and European Medicines Agency, including the US FDA Adverse Event Reporting System, drug safety, pharmacokinetic, efficacy, activity, and metabolizing enzyme and transporter data. The data sources of PharmaPendium for drug metabolizing enzymes and transporters include FDA approval packages, European Medicines Agency approval documents, FDA Advisory Committee Documents, and PharmaPendium Published MET (literature sources) (https://service.elsevier.com/app/answers/detail/a_id/29412/supporthub/ pharmapendium/kw/source/). Although PharmaPendium is a good resource for information about the DMETs and drug substrate, the gene symbols and enzyme names are not standardized or updated and contain mixed symbols and names. A rigorous manual curation of these gene symbols was performed to develop a comprehensive list of genes encoding DMETs in the rat. In brief, all data related to DMETs and their substrate for all species were exported from PharmaPendium [PharmaPendium master data-a total of 264,312 entries (rows) and 26 columns; accessed on June 2, 2015]. From this list, unique entries based on "Drug name," "Data Type," "Enzyme/Transporter," and "Species" columns were retained (25,646 entries). Then, unique entries based on only "Enzyme/Transporter" and "Species" were extracted (925 entries). All nonspecific names were then removed, and DMETs for only rat and humans were retained (443 entries). These gene names and symbols were mapped to the most up-to-date human and rat gene annotations using National Center for Biotechnology Information (NCBI) "Gene" module, and manual update and correction of DMETs gene symbols were performed to match the rat gene symbol annotation. These gene symbols were updated/corrected/annotated for the rat in six steps: 1) if the symbols were an exact match to the most up-to-date symbols from NCBI, then they were kept as is; 2) some symbols were old notations, and they were updated with the latest annotation; 3) some of the DMETs had gene names (e.g., "alcohol dehydrogenase") instead of gene symbols; they were substituted with all the isoforms of that gene; 4) genes that did not have a corresponding orthologous gene symbol in rat were substituted by homologous genes (to human genes) using the "Homologene" module of NCBI; 5) some gene symbols were misspelled, which was corrected manually; and 6) two genes had no corresponding exact match or orthologous or homologous genes in rats and were deleted. After all these steps were performed, a final list of 336 genes encoding DMETs was prepared (Supplemental Table 1).

The PharmaPendium master data contained information on 1197 unique drugs and their associated metabolizing DMETs (gene symbols). These data were extracted to allow association between drugs and the 336 DMETs.

Gene Expression Data and Statistical Comparison Between Female and Male. The expression profiles of 336 DMETs were examined in a comprehensive whole genome hepatic transcript profile data set of F344 rats, which contains data from nine ages ( 2 weeks to 2 years of age) and both sexes (Kwekel et al., 2010). This data set, available at the NCBI Gene Expression Omnibus data base with accession GEO21335, contained transcript profiles for 298 of these 336 DMET genes (Supplemental Table 1), and these normalized gene expression profiles were extracted for further analysis. Principal component analysis was performed in ArrayTrack (Tong et al., 2003; Fang et al., 2009), the FDA's relational data base for genomic data storage, processing, analysis, and visualization on log2tranformed, normalized intensity values. ArrayTrack is free and publicly available (https://www.fda.gov/science-research/bioinformatics-tools/arraytracktm-hca-pcastandalone-package-powerful-data-exploring-tools). Statistical comparisons ( $t$ test) between expression data of female and male for each of four adult age groups $(8$, 15, 21, and 52 weeks of age) were performed using SAS 9.3 (SAS Institute Inc., Cary, NC). Genes were considered to be differentially expressed between female and male at any one of the four ages if the $t$ test $P$ value was $<0.05$ and fold ratio (female to male or male to female) was $>2$. Genes that were differentially expressed between female and male rats at all four adult ages were considered as sexually dimorphic genes for adult rats (Supplemental Table 2).

Animal Care. Fischer 344 rats (10-13 weeks of age; body weights of females were $160-180 \mathrm{~g}$ and males $260-280 \mathrm{~g}$ ) were provided by the FDA National Center for Toxicological Research breeding colony. Animal care and experimental procedures were approved by the National Center for Toxicological Research Institutional Animal Care and Use Committee. The rats were separated by sex and group-housed in polycarbonate cages using hardwood chip bedding. Filtered tap water was provided ad libitum, and animals were fed NIH-41 irradiated diet ad libitum. Environmental controls were set to maintain temperature at $22 \pm 4{ }^{\circ} \mathrm{C}$, with relative humidity of $40 \%-70 \%$ with a 12 -hour light/dark cycle.

Rat Hepatocyte Isolation. A two-step perfusion method, as detailed in a previous publication, was used to isolate rat hepatocytes (Shi et al., 2011). Briefly, sodium pentobarbital ( $75 \mathrm{mg} / \mathrm{kg}$, i.p.) was used to anesthetize the rat, and the liver was perfused via a catheter inserted into the inferior vena cava. The buffer was composed of $137 \mathrm{mM} \mathrm{NaCl}, 5.4 \mathrm{mM} \mathrm{KCl}, 0.5 \mathrm{mM} \mathrm{KH_{2 }} \mathrm{PO}_{4}, 0.6 \mathrm{mM}$ $\mathrm{Na}_{2} \mathrm{PO}_{4}, 25 \mathrm{mM} \mathrm{NaHCO}, 5 \mathrm{mM}$ glucose, $5 \mu \mathrm{g} / \mathrm{ml}$ bovine insulin, $50 \mathrm{U} / \mathrm{ml}$ penicillin, and $50 \mu \mathrm{g} / \mathrm{ml}$ streptomycin. After approximately 10 minutes, $0.03 \%$ collagenase (type IV), $2 \mathrm{mM} \mathrm{CaCl}_{2}$, and $0.01 \%$ soybean trypsin inhibitor 
were added to the perfusion buffer. The digested liver was homogenized, and the suspension was centrifuged at $50 \mathrm{~g}$ for 3 minutes. The pellets were resuspended in $90 \%$ isotonic Percoll solution ( $\mathrm{pH} 7.0$ ) and centrifuged at $100 \mathrm{~g}$ for 8 minutes to purify the hepatocyte. Finally, the cells were suspended in Williams' E medium supplemented with $5 \mu \mathrm{g} / \mathrm{ml}$ insulin, $5 \mu \mathrm{g} / \mathrm{ml}$ holo-transferrin, $25 \mathrm{nM}$ dexamethasone, and $5 \mathrm{ng} / \mathrm{ml}$ sodium selenous acid. The cells were immediately used for suspension culture or were plated for prolonged culture as monolayers. All experiments were repeated using cells from at least three males and three females.

Hepatocytes in Suspension Culture for Drug Metabolism Measurements. The cells were diluted to $2 \times 10^{6} \mathrm{cell} / \mathrm{ml}$ and placed in 96 -well plates $(50 \mu \mathrm{l}$ per well). The test drugs were obtained from Sigma-Aldrich (Saint Louis, MO), and were of USP reference standard quality. Stock solutions were freshly prepared in DMSO and diluted at 1:1000 using culture medium to achieve 2-fold the final treatment concentrations. This working solution was added to the 96-well plate (50 $\mu 1$ per well) containing cell suspensions. The final concentrations in the cultures were $1 \mu \mathrm{M}$ for buspirone, fentanyl, glimepiride, irinotecan, pravastatin, tamsulosin, and terfenadine and $5 \mu \mathrm{M}$ for azelastine, doxorubicin, and tazarotene. The compound 7-ethoxycoumarin $(2 \mu \mathrm{M})$ was used as a positive control. The cells were placed on a microplate shaker in an incubator and cultured under $5 \% \mathrm{CO}_{2}$ at $37^{\circ} \mathrm{C}$. After $5,15,30,60,90$, and 120 minutes, $100 \mu \mathrm{l}$ acetonitrile containing $50 \mathrm{ng} / \mathrm{ml}$ carbamazepine and $100 \mathrm{ng} / \mathrm{ml}$ tolbutamide was added to the wells to stop the reaction. The plates were placed at $4^{\circ} \mathrm{C}$ for 30 minutes and then centrifuged at $800 \mathrm{~g}$ for 10 minutes. Part of the supernatant $(135 \mu \mathrm{l})$ was transferred to a new 96-well plate, and the samples were dried using a SpeedVac under $4^{\circ} \mathrm{C}$. The samples were then shipped on dry ice to Sano Informed Prescribing, Inc. (Franklin, TN) for measuring the drug/metabolite levels. Hepatocytes from three male and three female rats were prepared from untreated control cultures by centrifugation and stored at $-80^{\circ} \mathrm{C}$ for quantitative polymerase chain reaction (qPCR) and Western analysis.

Hepatocytes Cultured as Monolayers for Drug Cytotoxicity Determination. The hepatocytes were diluted to $2 \times 10^{5} \mathrm{cell} / \mathrm{ml}$ and then seeded at a density of 25,000 cells per well in white 96 -well plates coated with type I collagen. The cells were incubated overnight at $37^{\circ} \mathrm{C}$ under a relative humidity of $95 \%$ and $5 \% \mathrm{CO}_{2}$. The original culture medium was discarded and replaced with new medium containing the test drugs. The test compounds were freshly prepared as $1000 \times$ stock solutions in DMSO. The final concentrations of test drugs were 1,2, $4,6,8,10,15,20,25$, and 30 -fold the maximum serum concentration in humans receiving a clinical dose of the drug ( $C_{\max }$ total concentration). Ideally, the concentrations to be tested in cultured hepatocytes should mimic the liver tissue levels of the drugs. However, the liver concentrations of most drugs are unknown. A literature survey found that many drugs accumulated in the liver at concentrations of 10-30-fold $C_{\max }$ (McIntyre, 2014; Venuto et al., 2017; Paech et al., 2018). It was therefore decided that a threshold of 30 -fold $C_{\max }$ would be used in this study. $C_{\max }$ values for the set of 33 drugs metabolized by one or two P450 enzymes encoded by sexually dimorphic mRNAs that were soluble in DMSO and commercially available are shown in Supplemental Table 3. DMSO $(0.1 \%)$ was used as the vehicle control. After 8 and 24 hours, three cytotoxicity endpoints were measured as described below.

Cytotoxicity Endpoints. ATP levels and Caspase 3/7 activity were measured using the CellTiter-Glo Luminescent Cell Viability Assay kit and Caspase-Glo 3/7 Assay kit (Promega, Madison, WI), respectively. Briefly, half of the medium was removed, and $50 \mu \mathrm{l}$ per well assay buffer was added. After 30 minutes, the luminescence signal was determined using a Tecan plate reader (Infinite M200 PRO). The signal from DMSO-treated cells was set as $100 \%$ (Zhang et al., 2018). Lactate dehydrogenase (LDH) release was measured using a procedure detailed in previous publications (Shi et al., 2011; Zhang et al., 2018). Briefly, $7 \mu$ l culture medium was taken to measure the leaked $\mathrm{LDH}$; then the cells were lysed using $1 \%$ Triton $\mathrm{X}-100$ to determine the total $\mathrm{LDH}$ activity. The ratio between leaked LDH and total LDH activity was used to calculate cell viability (Shi et al., 2011; Zhang et al., 2018).

Confirmation of Differentially Expressed P450 Genes in Primary Hepatocytes by Real-Time qPCR. RNA samples were extracted from both monolayer and suspension cell cultures of untreated rat liver primary hepatocytes using Qiagen miRNeasy Mini Kits (Qiagen, Valencia, CA) following the manufacturer's protocol. Monolayer cell culture samples were taken for RNA extraction after $0,4,20,22,24$, and 26 hours of culture. Suspension cell culture samples were taken for RNA extraction after 0, 30, 60, 90, and 120 minutes. RNA quality was evaluated using the Agilent 2100 Bioanalzyer (Agilent Technologies,
Palo Alto, CA), and RNA integrity numbers ranged from 8.6 to 10, with an average of 9.3. These RNA samples were used to assess the expression of four P450 genes (Cyp2c7, Cyp2c11, Сyp3a2, and Cyp3a62), which showed hepatic sexual dimorphism in a previous in vivo rat study (Kwekel et al., 2010; Yu et al., 2014). TaqMan gene expression probes for these P450 mRNAs (Cyp $2 c 7$, Rn01529602_mH; Cyp2c11, Rn01502203_m1; Cyp3a2, Rn00756461_m1 and Cyp3a62, Rn01409578_m1) and endogenous control, glyceraldehyde-3-phosphate dehydrogenase ( $\mathrm{Rn} 1775763$ g1), were purchased from Thermo Fisher Scientific, Inc. (Hanover Park, IL). In brief, $900 \mathrm{ng}$ total RNA from each sample was reverse transcribed to cDNA using the High Capacity RNA-to-cDNA Kit (Thermo Fisher) in a 96-well plate on a GeneAmp PCR System 9700 (Thermo Fisher). Each cDNA sample was then diluted 10 -fold to $200 \mu 1$. Nine microliters of diluted cDNA sample was used for real-time PCR in a $20 \mu 1$ reaction on an ABI 7900HT Fast Real-Time PCR System using TaqMan Universal Master Mix II with UNG kit (Thermo Fisher). Hepatocyte cultures from three male and three female rats were used for qPCR, and each culture was measured in duplicate. The $2^{-\Delta \Delta C t}$ value (Livak and Schmittgen, 2001) of each sample was normalized to the lowest expression value for each gene before downstream analysis. These normalized values were used to compute the expression changes between sexes at the different culture time points. Student's $t$ test was used to calculate the statistical significance $(P<0.05)$

Western Blot Analysis. Monolayer cell culture samples were taken for protein extraction after $0,4,20,22,24$, and 26 hours of culture. Suspension cell culture samples were taken for protein extraction after $0,30,60,90$, and 120 minutes. The hepatocytes were lysed and centrifuged as detailed previously (Weng et al., 2015). The resulting proteins were mixed with Laemmli buffer (Laemmli, 1970) and heated in a water bath at $95^{\circ} \mathrm{C}$ for 5 minutes before sodium dodecyl sulfate polyacrylamide gel electrophoresis. Thirty micrograms of protein were loaded in each lane and transferred to polyvinylidene difluoride membranes after electrophoresis. The primary monoclonal antibodies against rat CYP3A2 (catalog number P3A2PT from Detroit R\&D, Inc, Detroit, MI) or CYP2C11 (catalog number P2C11PT from Detroit R\&D, Inc) were mixed with the anti-actin antibody (catalog number ab3280 from Abcam) and incubated with the polyvinylidene difluoride membrane for about 18 hours. All the primary antibodies were diluted 1000-fold for use. The membrane was then incubated with the secondary antibody for 1 hour, and the bands were visualized using an Amersham Imager 600 (GE Healthcare Life Sciences, Pittsburgh, PA).

Measurement of Drugs in Hepatocyte Suspension Cultures. Drug and metabolite measurements were performed by Sano Informed Prescribing (currently known as Precera Bioscience). All samples were analyzed via electrospray ionization on a Sciex QTRAP 5500 instrument (Foster City, CA) that was coupled with Shimadzu LC-30AD pumps (Columbia, MD) and a Leap Technologies CTC PAL autosampler (Carrboro, NC). Analytes were separated by gradient elution using a Phenomenex C18 $2.1 \times 50 \mathrm{~mm}, 1.7 \mu \mathrm{m}$ column (Torrance, CA) thermostated at $50^{\circ} \mathrm{C}$. High-performance liquid chromatography mobile phase $\mathrm{A}$ was $10 \mathrm{mM}$ ammonium formate in water, and mobile phase $\mathrm{B}$ was $0.1 \%$ formic acid in acetonitrile. The gradient started at $30 \% \mathrm{~B}$ after a 0.2 -minute hold and was linearly increased to $90 \%$ B over 0.8 minute, held at $90 \%$ B for 0.5 minute, and returned to $30 \% \mathrm{~B}$ in 0.1 minute followed by a re-equilibration ( 0.9 minute). At the time of analysis, the samples were reconstituted with initial mobile phase. The total run time was 2.5 minutes, and the high-performance liquid chromatography flow rate was $0.5 \mathrm{ml} / \mathrm{min}$. The source temperature was set at $500^{\circ} \mathrm{C}$, and mass spectral analyses were performed using multiple reaction monitoring, with transitions and voltages specific for each compound utilizing a TurboV source (Table 1). All data were collected using Sciex Analyst 1.6.2 and analyzed using MultiQuant 3.0.1 software. Each compound was assayed in triplicate within the same 96-well plate.

Calculation of Half-Lives for Drugs. Half-life was calculated using elimination rate constant $(\lambda$, which is the slope of drug concentration during incubation with the primary hepatocytes) from a concentration-time plot. The concentration of drugs in hepatocyte culture was measured at 5, 15, 30, 60, 90, and 120 minutes for both sexes ( $n=3$ rats for each sex; three technical replicates for each culture condition, which were averaged). The concentration of drugs at each time point was transformed into percent remaining with respect to the 5-minute time point for each sex. The percent remaining data were converted to natural logarithm values to perform statistics using SAS/STAT software, version 14.1 of the SAS System for Windows (SAS Institute Inc.). The calculation of slope for individual male and female rats and testing for heterogeneity (or homogeneity) of 
TABLE 1

Mass transitions and voltages for quantitation of drugs

\begin{tabular}{|c|c|c|c|c|}
\hline Drug & Q1 & Q2 & $\mathrm{CE}$ & Mode \\
\hline & & & $\mathrm{V}$ & \\
\hline Azelastine & 382.1 & 112.2 & 35 & Positive \\
\hline Buspirone & 386.2 & 122.1 & 40 & Positive \\
\hline Doxorubicin & 544.1 & 361.1 & 20 & Positive \\
\hline Fentanyl & 337.2 & 188.2 & 50 & Positive \\
\hline Fexofenadine & 502.2 & 171.1 & 49 & Positive \\
\hline Glimepiride & 491.2 & 352.1 & 30 & Positive \\
\hline Irinotecan & 587.2 & 124.2 & 45 & Positive \\
\hline Phenytoin & 253.1 & 181.1 & 26 & Positive \\
\hline Pravastatin & 423.2 & 321.2 & -20 & Negative \\
\hline Tamsulosin & 410.2 & 229.1 & 30 & Positive \\
\hline Tazarotene & 352.1 & 294.2 & 56 & Positive \\
\hline Tazarotenic acid & 322.1 & 278.1 & -26 & Negative \\
\hline Terfenadine & 472.2 & 436.2 & 30 & Positive \\
\hline
\end{tabular}

$\mathrm{CE}$, collision energy.

slopes of regression line between males and females was performed using a generalized linear model procedure (Proc GLM) in SAS. In brief, the generalized linear model procedure used least squares analysis to fit the simple linear regression models and simultaneously estimate the intercepts and slopes for all rats. These slopes were used to calculate half-life $\left(t_{1 / 2}\right)$ of each drug for all male and female rats $(n=3)$ using the formula $t_{1 / 2}=\ln (2) / \lambda$. Furthermore, the half-life of each drug was compared between male and female rats $(n=3)$ using the $t$ test. Additionally, the amount of drug remaining at each time point was also compared between male and female rats using the $t$ test.

Comparison of slopes between male and female was performed using time and concentration as the main effect as well as the interaction (time* concentration) in the model to calculate an overall slope from the concentration-time plot using data from three male or three female rats for each time point. If the deviations of the groups' slopes from the overall slope were not all zero and the interaction effect was significant $(P<0.05)$, the slopes were not equal and there was significant difference between the slopes $(\lambda)$ for male and female drug metabolism over time.

Half-life was not calculated for terfenadine since formation of fexofenadine (major metabolite of terfenadine) was measured to assess the metabolism of terfenadine. A statistical difference in the slopes of formation of fexofenadine to test heterogeneity (or homogeneity) of slopes of regression line between male and female rats was determined using simple linear regression as described above (using the Proc GLM procedure in SAS).

\section{Results}

Sex-Biased Hepatic Expression of DMET Genes. Principal component analysis, utilizing the expression profiles of 298 DMET genes, was used to examine hepatic DMET gene expression across the life span and between the sexes of F344 rats. The DMET gene expression profile varies with both age and sex, with the largest sex difference observed between adults (8-52 weeks of age) (Fig. 1). Twenty-nine DMET genes were found to be differentially expressed between male and female adults at all four ages $(8,15,21$, and 52 weeks of age), with 17 expressed at a higher level in males than females (Table 2) and 12 expressed at a higher level in females than males (Table 3). These included genes involved in phase I and phase II metabolism, as well as transporters. Genes with the highest expression in males compared with females were Sult1e1, Cyp2a2, Cyp2c13, Cyp 2c11, and Cyp3a2 with a range of fold differences of 216-2497. The genes with the highest expression in females compared with males were Abcc3, Sult2a1, Abcd2, Adh6, and Cyp2c12 with a range of fold differences of 7.6-346. The 29 enzymes encoded by these differentially expressed genes metabolize or transport more than 600 drugs (Tables 2 and 3; Supplemental Table 2).

Drugs Metabolized by DMETs that Are Encoded by Sex-Biased Genes. Because a large number of drugs $(>600)$ are metabolized by these sexually dimorphic DMETs and many drugs are metabolized or transported by multiple enzymes or transporters, as a first step in evaluating whether expression patterns of DMET genes can be used to predict drug metabolism differences, we focused on drugs that are metabolized by only one or two P450s encoded by sex-different P450 mRNAs. Using Supplemental Table 2, 41 such drugs were identified, and they are metabolized by CYP3A2, CYP2C11, CYP3A62, or CYP2C7 (Table 4). The 41 drugs encompass a large variety of drug classes and include antihistamines, antineoplastics, and analgesics.

Prediction of Sex-Biased Drug Metabolism Based on Differential Gene Expression Profile. Based upon the differential gene expression levels of these P450s in males and females, we hypothesized that drug metabolism dependent on these P450s would be higher in the sex with the higher level of the P450 mRNA. Eleven of the drugs in Table 4 were

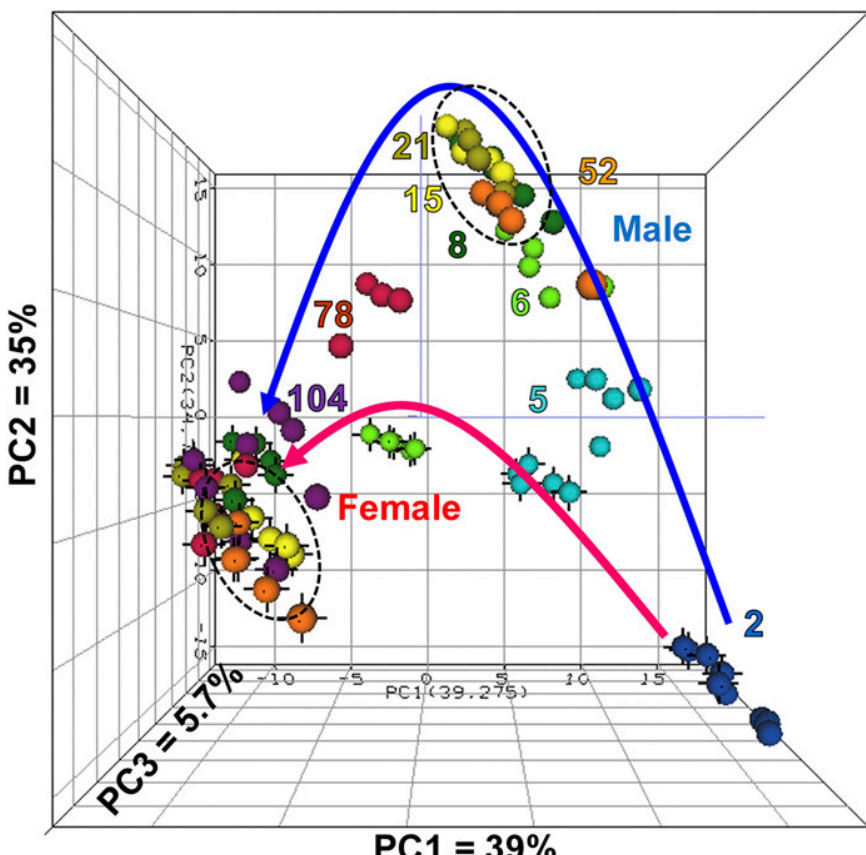

\section{$\mathrm{PC} 1=39 \%$}

Fig. 1. Principal component (PC) analysis of expression of 298 drug metabolism/ transporter genes. Expression of hepatic drug metabolism genes varies with sex and age in untreated F344 rats. Each sphere represents the hepatic expression profile of a single rat, with females represented by black vertices and males without. Numbers and colors indicate age (week). Arrowed line indicates trajectory of profiles with age for males (blue line) and females (red line). Dotted circles show large expression profile difference between males and females at ages of 8-52 week. 
TABLE 2

Male-biased expression of genes encoding DMETs in liver of adult rats

\begin{tabular}{|c|c|c|c|c|}
\hline Gene Symbol & Description & Human ortholog & $\begin{array}{c}\text { Number of } \\
\text { drugs }^{a}\end{array}$ & $\begin{array}{l}\text { Fold difference in expression } \\
\text { (male to female })^{b}\end{array}$ \\
\hline Сур3а2 & Cytochrome P450 & CYP $3 A 4$ & 487 & 2497 \\
\hline Cyp $2 c 11$ & Cytochrome P450 & CYP $2 C 18$ & 424 & 2239 \\
\hline Cyp $2 c 13$ & Cytochrome P450 & & 3 & 1232 \\
\hline Cyp $2 a 2$ & Cytochrome P450 & & 2 & 237 \\
\hline Sultle1 & Sulfotransferase & SULT1E1 & 4 & 216 \\
\hline Slc $22 a 8$ & Solute carrier & $S L C 22 A 8$ & 223 & 46.9 \\
\hline Car3 & Carbonic anhydrase & $C A 3$ & 1 & 30.4 \\
\hline Cyp3a18 & Cytochrome P450 & & 2 & 18.6 \\
\hline Cур $4 a 2$ & Cytochrome P450 & & 34 & 18.6 \\
\hline Akrlc3 & Aldo-keto reductase & $A K R 1 C 3$ & 1 & 16.8 \\
\hline$H s d 11 b 1$ & Hydroxysteroid 11-beta dehydrogenase 1 & $H S D 11 B 1$ & 1 & 10.5 \\
\hline Slc22a25 & Solute carrier & $S L C 22 A 25$ & 53 & 9.2 \\
\hline Cyp $4 a 8$ & Cytochrome P450 & & 1 & 8.8 \\
\hline Cур $3 a 62$ & Cytochrome P450 & & 224 & 6.2 \\
\hline Sult1c3 & Sulfotransferase & SULTIC3 & 2 & 3.2 \\
\hline Tymp & Thymidine phosphorylase & TYMP & 1 & 3.0 \\
\hline Pldl & Phospholipase D1 & PLD1 & 1 & 2.5 \\
\hline
\end{tabular}

${ }^{a}$ Number of drugs metabolized by the enzyme/transporter. Drugs are listed in Supplemental Table 2.

${ }^{b}$ Calculated from microarray data (Kwekel et al., 2010) as average of expression at 8, 15, 21, and 52 wk of age.

selected for testing of this hypothesis in male and female rat primary hepatocytes: doxorubicin, irinotecan, phenytoin, azelastine, buspirone, fentanyl, glimepiride, pravastatin, tamsulosin, terfenadine, and tazarotene. Selection criteria included a diversity of drug classes and drugs metabolized by at least one of the sexually dimorphic P450s.

Testing of Predictions of Sex-Biased Drug Metabolism in Male and Female Primary Rat Hepatocytes. Hepatocytes were isolated from male and female adult F344 rats of 10-13 weeks of age for analysis of sex-different drug metabolism.

Verification of Sex-Biased P450 Gene Expression in Primary Rat Hepatocytes. To verify that the cultured primary rat hepatocytes expressed the same relative sex-different levels of P450 mRNAs as the liver of F344 rats, Cyp2c7, Cyp2c11, Cyp3a2, and Cyp3a62 mRNAs were measured during the 2-hour cell incubation period in both the suspension cultures (used for drug metabolism measurements) and monolayer cultures (used for cytotoxicity measurements). As can be seen in Fig. 2, the relative levels of these P450 mRNAs in suspension cultures were similar to what was reported in the livers of F344 rats (Tables 2 and 3). Cyp3a2 and Cyp2c11 mRNAs were expressed in male primary hepatocytes and liver at thousands of times higher levels than in females. The qPCR measurements in the primary hepatocytes showed a larger difference between males and females $(\sim 20,000$-fold difference for Cyp2c11 and $\sim 11,000$-fold difference for Cyp3a2) than the microarray measurements ( $\sim 2200$-fold for Cyp2c11 and $\sim 2500$-fold for Cyp3a2), possibly because of the higher sensitivity and dynamic range of the qPCR assay compared with the microarray (Kwekel et al., 2010) method. Cyp3a62 mRNA was expressed 5-6-fold higher in both male primary hepatocytes and liver than in female hepatocytes and liver. Cyp2c7 mRNA was expressed 3-5-fold higher in female primary hepatocytes and liver than in male primary hepatocytes and liver. Stable levels of each P450 mRNA were maintained in both male and female cells during the full 2-hour incubation period. Similar and consistent expression differences of the $\mathrm{P} 450 \mathrm{mRNAs}$ were found in the monolayer cultures with the fold difference between male and female levels for Cyp3a2, Cyp2c11, Cyp3a62, and Cyp2c7 being 12,000, 39,000, 8.7, and 2.8 , respectively, although there was significant decline in absolute expression by 20 hours (Supplemental Fig. 1). Thus, the primary hepatocytes from male and female rats mimic relative mRNA levels of the intact rat liver.

Sex-Biased P450 Protein Expression in Primary Rat Hepatocytes. Antibodies were commercially available for two of the rat P450 proteins (CYP3A2 and CYP2C11) encoded by sexually dimorphic mRNAs. Western blot analysis of extracts from male and female primary hepatocytes during the 2-hour incubation of suspension cultures showed higher levels of both proteins in male cells than female cells (Fig. 3), with the female cells having undetectable levels of these proteins. Stable

TABLE 3

Female-biased expression of genes encoding DMETs in liver of adult rats

\begin{tabular}{|c|c|c|c|c|}
\hline Gene symbol & Description & Human ortholog & $\begin{array}{l}\text { Number of } \\
\text { drugs }^{a}\end{array}$ & $\begin{array}{l}\text { Fold difference in expression } \\
\text { (female to male })^{b}\end{array}$ \\
\hline Cyp $2 c 12$ & Cytochrome P450 & & 4 & 346 \\
\hline Adh6 & Alcohol dehydrogenase 6 & ADH6 & 10 & 29.1 \\
\hline$A b c d 2$ & ATP-binding cassette & $A B C D 2$ & 1 & 22.8 \\
\hline Sult2al & Sulfotransferase & SULT2A1 & 4 & 18.8 \\
\hline$A b c c 3$ & ATP-binding cassette & $A B C C 3$ & 23 & 7.6 \\
\hline Сур $3 a 9$ & Cytochrome P450 & CYP3A5 & 9 & 6.3 \\
\hline Prss32 & Protease, serine, 32 & & 1 & 5.7 \\
\hline Pla2g16 & Phospholipase A2 & $P L A 2 G 16$ & 1 & 4.5 \\
\hline Bche & Butyrylcholinesterase & BCHE & 2 & 4.0 \\
\hline Slc $7 a 5$ & Solute carrier & SLC7A5 & 2 & 4.0 \\
\hline Cyp $2 c 7$ & Cytochrome P450 & & 254 & 3.2 \\
\hline Ces $2 e$ & Carboxylesterase $2 \mathrm{E}$ & & 1 & 2.8 \\
\hline
\end{tabular}

${ }^{a}$ Number of drugs metabolized by the enzyme/transporter. Drugs are listed in Supplemental Table 2

${ }^{b}$ Calculated from microarray data (Kwekel et al., 2010) as average of expression at $8,15,21$, and 52 wk of age. 
TABLE 4

Forty-one drugs metabolized by sexually dimorphic P450s

\begin{tabular}{|c|c|c|c|c|c|}
\hline \multirow{2}{*}{ Drug } & \multirow{2}{*}{ Drug class } & \multicolumn{2}{|c|}{ DMET 1} & \multicolumn{2}{|c|}{ DMET 2} \\
\hline & & DMET & FD & DMET & FD \\
\hline Amlodipine $^{a}$ & Ca channel blocker & Cyp3a2 & $\sim 2500 \mathrm{M}>\mathrm{F}$ & & \\
\hline Astemizole $^{a, b}$ & Antihistamine & Сур $3 a 2$ & $\sim 2500 \mathrm{M}>\mathrm{F}$ & & \\
\hline Azelastine $^{a, b}$ & Antihistamine & Cyp $2 c 11$ & $\sim 2200 \mathrm{M}>\mathrm{F}$ & Сур3a2 & $\sim 2500 \mathrm{M}>\mathrm{F}$ \\
\hline Beclomethasone $^{a, b}$ & Corticosteroid & Cур $3 a 2$ & $\sim 2500 \mathrm{M}>\mathrm{F}$ & & \\
\hline Buspirone $^{a}$ & Anxiolytic & Сур $3 a 2$ & $\sim 2500 \mathrm{M}>\mathrm{F}$ & & \\
\hline Cetirizine $^{a}$ & Antihistamine & Сур $3 a 2$ & $\sim 2500 \mathrm{M}>\mathrm{F}$ & & \\
\hline Clonazepam & Antiepileptics & Cyp3a62 & $\sim 6 \mathrm{M}>\mathrm{F}$ & & \\
\hline Dextromethorphan $^{a, b}$ & Cough suppressant & Сур $3 a 62$ & $\sim 6 \mathrm{M}>\mathrm{F}$ & & \\
\hline $\operatorname{Digoxin}^{a}$ & Cardiac glycoside & Сур $3 a 2$ & $\sim 2500 \mathrm{M}>\mathrm{F}$ & & \\
\hline Doxorubicin $^{a, b}$ & Antineoplastic & Сур $3 a 2$ & $\sim 2500 \mathrm{M}>\mathrm{F}$ & & \\
\hline Ebastine $^{a}$ & Antihistamine & Сур $3 a 2$ & $\sim 2500 \mathrm{M}>\mathrm{F}$ & & \\
\hline Ethinyl estradiol $^{a, b}$ & Hormone & Cур3а62 & $\sim 6 \mathrm{M}>\mathrm{F}$ & Сур $3 a 2$ & $\sim 2500 \mathrm{M}>\mathrm{F}$ \\
\hline Etonogestrel & Hormone & Сур $3 a 2$ & $\sim 2500 \mathrm{M}>\mathrm{F}$ & & \\
\hline Fentanyl $^{a}$ & Analgesics opioid & Cyp3a62 & $\sim 6 \mathrm{M}>\mathrm{F}$ & Сур $3 a 2$ & $\sim 2500 \mathrm{M}>\mathrm{F}$ \\
\hline Fexofenadine $^{a, b}$ & Antihistamine & Cур3а62 & $\sim 6 \mathrm{M}>\mathrm{F}$ & Сур $3 a 2$ & $\sim 2500 \mathrm{M}>\mathrm{F}$ \\
\hline Flunisolide $^{a}$ & Corticosteroid & Cyp3a2 & $\sim 2500 \mathrm{M}>\mathrm{F}$ & & \\
\hline Fosphenytoin & Antiepileptic & Cyp $2 c 11$ & $\sim 2200 \mathrm{M}>\mathrm{F}$ & & \\
\hline Glimepiride $^{a, b}$ & Antihyperglycemic & Cyp $2 c 11$ & $\sim 2200 \mathrm{M}>\mathrm{F}$ & & \\
\hline Hydrocodone & Analgesics opioid & Cур $3 a 2$ & $\sim 2500 \mathrm{M}>\mathrm{F}$ & & \\
\hline Ibutilide $^{a, b}$ & Antiarrhythmic & Cyp $3 a 2$ & $\sim 2500 \mathrm{M}>\mathrm{F}$ & & \\
\hline Irinotecan $^{a, b}$ & Antineoplastic & Сур $3 a 2$ & $\sim 2500 \mathrm{M}>\mathrm{F}$ & & \\
\hline Ketoprofen & NSAID & Cyp $2 c 11$ & $\sim 2200 \mathrm{M}>\mathrm{F}$ & & \\
\hline Levobupivacaine $^{a}$ & Anesthetic, local & Сур $3 a 2$ & $\sim 2500 \mathrm{M}>\mathrm{F}$ & & \\
\hline Lidocaine $^{a}$ & Anesthetic, local & Сур $3 a 2$ & $\sim 2500 \mathrm{M}>\mathrm{F}$ & & \\
\hline Loratadine $^{a}$ & Antihistamine & Сур $3 a 2$ & $\sim 2500 \mathrm{M}>\mathrm{F}$ & & \\
\hline Medroxyprogesterone $^{a}$ & Hormone & Сур $3 a 2$ & $\sim 2500 \mathrm{M}>\mathrm{F}$ & & \\
\hline Mometasone $^{a}$ & Corticosteroid & Сур $3 a 2$ & $\sim 2500 \mathrm{M}>\mathrm{F}$ & Сур3а62 & $\sim 6 \mathrm{M}>\mathrm{F}$ \\
\hline Naproxen & NSAID & Cyp $2 c 11$ & $\sim 2200 \mathrm{M}>\mathrm{F}$ & & \\
\hline Nifedipine ${ }^{a, b}$ & Ca channel blocker & Cур $3 a 2$ & $\sim 2500 \mathrm{M}>\mathrm{F}$ & & \\
\hline Nimodipine $^{a, b}$ & Ca channel blocker & Сур $3 a 2$ & $\sim 2500 \mathrm{M}>\mathrm{F}$ & & \\
\hline Norethindrone $^{a}$ & Hormone & Сур $3 a 2$ & $\sim 2500 \mathrm{M}>\mathrm{F}$ & & \\
\hline Oxybutynin ${ }^{a}$ & Anticholinergic & Cур $3 a 2$ & $\sim 2500 \mathrm{M}>\mathrm{F}$ & & \\
\hline Phentermine & Antiobesity & Сур $3 a 2$ & $\sim 2500 \mathrm{M}>\mathrm{F}$ & & \\
\hline Phenytoin $^{a, b}$ & Antiepileptic & Cyp $2 c 11$ & $\sim 2200 \mathrm{M}>\mathrm{F}$ & & \\
\hline Pravastatin $^{a, b}$ & Lipid modifying & Cур $3 a 2$ & $\sim 2500 \mathrm{M}>\mathrm{F}$ & & \\
\hline Sertindole ${ }^{a, b}$ & Antipsychotic & Сур3а62 & $\sim 6 \mathrm{M}>\mathrm{F}$ & & \\
\hline Tamsulosin ${ }^{a, b}$ & Antiadrinergic & Сур $3 a 2$ & $\sim 2500 \mathrm{M}>\mathrm{F}$ & & \\
\hline Tazarotene $^{a, b}$ & Antipsoriatic & Cyp $2 c 7$ & $\sim 3 \mathrm{~F}>\mathrm{M}$ & & \\
\hline Terfenadine $\mathrm{e}^{a, b}$ & Antihistamine & Сур $3 a 2$ & $\sim 2500 \mathrm{M}>\mathrm{F}$ & & \\
\hline Trazodone $^{a, b}$ & Antidepressant & Cyp3a2 & $\sim 2500 \mathrm{M}>\mathrm{F}$ & & \\
\hline Triazolam & Antianxiety & Cyp3a62 & $\sim 6 \mathrm{M}>\mathrm{F}$ & & \\
\hline
\end{tabular}

FD, fold difference in gene expression level; $\mathrm{F}>\mathrm{M}$, expression is higher in females than in males; $\mathrm{M}>\mathrm{F}$, expression is higher in males than in females; NSAID, nonsteroidal antiinflammatory drug.

${ }^{a}$ Thirty-three drugs tested for cytotoxicity in hepatocytes from one male and one female F344 rat.

${ }^{b}$ Nineteen drugs selected for cytotoxicity testing in hepatocytes from a total of three male and three female F344 rats.

levels of the $\mathrm{P} 450$ proteins were maintained in the male cells during the full 2-hour incubation period. Similarly, stable sex-different expression of the P450 proteins was seen in the cultures of attached cells used for cytotoxicity assays (Supplemental Fig. 2), with the proteins not detectable in female cells. Thus, the primary hepatocytes are expressing sexdifferent amounts of $\mathrm{P} 450$ proteins consistent with the relative levels of hepatic P450 mRNA in male and female F344 rats.

Drug Metabolism in Male and Female Primary Rat Hepatocytes. Eleven of the drugs with predicted sex-different P450 metabolism were incubated with suspension cultures of primary hepatocytes from adult male and female F344 rats for 2 hours. Drug concentration remaining was measured at six time points $(5,15,30,60,90$, and 120 minutes) during this period, and half-lives were determined. The concentration of terfenadine could not accurately be measured, and, therefore, it was not possible to calculate the half-life for the compound. Instead, the formation of its Cyp $3 a 2$ metabolite fexofenadine was measured. The kinetics of metabolism of each drug (except terfenadine) is shown in Figs. 4 and 5. The formation of fexofenadine from terfenadine during the 2-hour incubation is shown in Fig. 6.
Three Drugs with Long Half-Lives. Three of the 11 drugs were not appreciably metabolized by either male or female rat primary hepatocytes during the 2-hour incubation period (Fig. 4C, doxorubicin; Fig. 4F, irinotecan; and Fig. 4G, phenytoin). The extent of metabolism of irinotecan and phenytoin was less than $10 \%$, and the extent of metabolism of doxorubicin was less than $30 \%$. Thus, accurate half-lives and possible differences between males and females could not be determined for these three drugs.

Sexually Dimorphic Metabolism of Six of Seven Drugs. The metabolism of azelastine, buspirone, fentanyl, glimepiride, pravastatin, and tamsulosin over the 2-hour incubation period in primary rat hepatocytes is shown in Fig. 4, A, B, D, E, H, and I, respectively. With the exception of the four drugs discussed above (terfenadine, irinotecan, phenytoin, and doxorubicin), the half-lives of seven drugs were determined and are shown in Table 5. Five drugs showed the predicted sexual dimorphism of greater metabolic rate in males than females (azelastine, 75\% slower in females; buspirone, $89 \%$ slower in females; fentanyl, $49 \%$ slower in females; glimepiride, $70 \%$ slower in females; and tamsulosin, 39\% slower in females) with $P$ values $<0.05$.

Because of difficulties in consistently measuring terfenadine, the formation of fexofenadine, the Cyp $3 a 2$ major metabolite of terfenadine, 
A

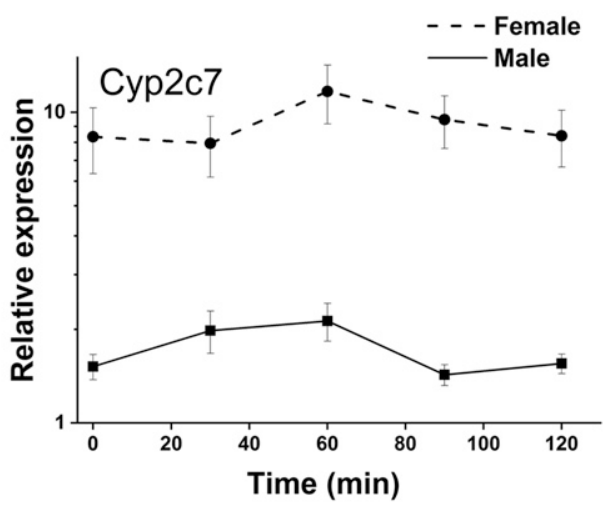

C

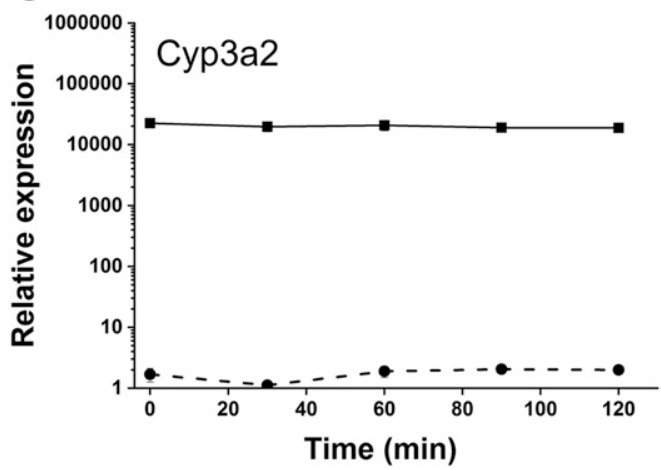

B
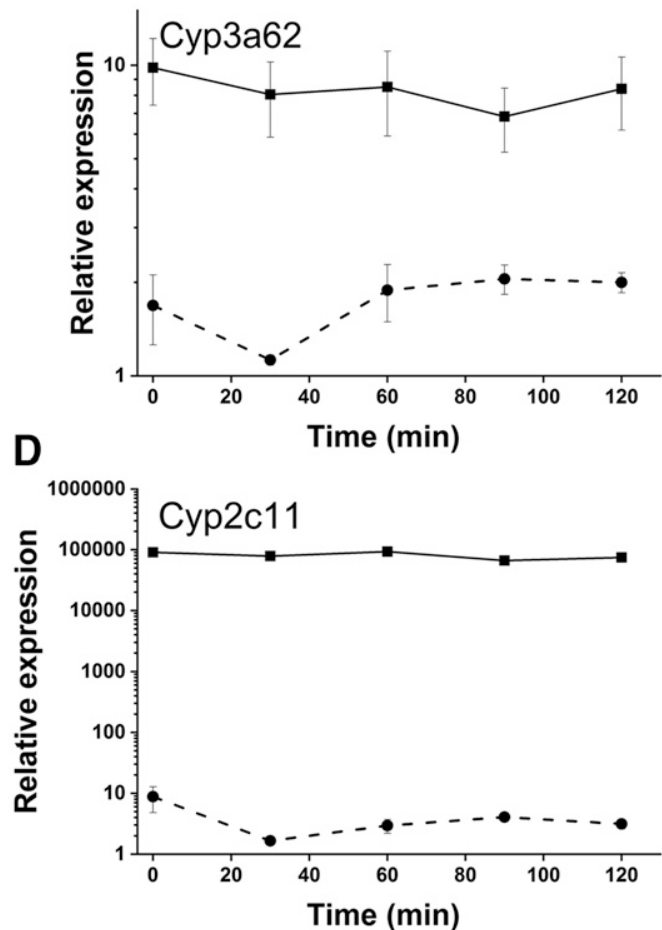

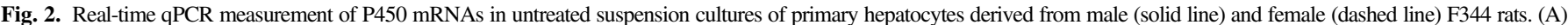

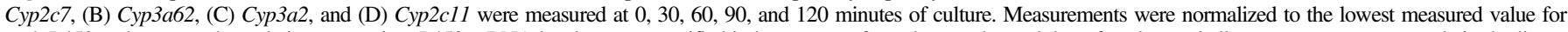

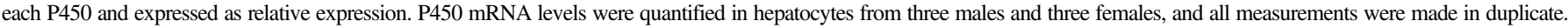

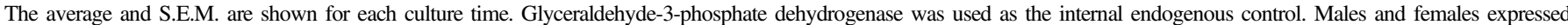
significantly different levels of mRNA coding for Cyp2c7 $(P<0.01)$, Cyp3a62 $\left(P<10^{-5}\right)$, Cyp3a2 $\left(P<10^{-30}\right)$, and Cyp2c11 $\left(P<10^{-28}\right)$ by Student's $t$ test.

was measured in male and female primary rat hepatocyte cultures. The kinetics of the metabolism in hepatocytes from males and females is shown in Fig. 6. The formation of fexofenadine was significantly more rapid in males than females with a slope more than 4 times greater in males than females $(P<0.0001)$. Thus, male metabolism of terfenadine was more rapid than female, as predicted from the transcript data.

The metabolism of tazarotene appeared to be rapid and identical in male and female rat primary hepatocytes (male, $t_{1 / 2}=17$ minutes; female, $t_{1 / 2}=$ 16 minutes, Fig. 5A; Table 5), with no apparent sex difference. A literature review revealed that tazarotene is hydrolyzed by esterases in liver, as well as the blood, of both humans and rats to its active metabolite, tazarotenic acid (Madhu et al., 1997). The formation of tazarotenic acid from tazarotene was, therefore, examined in both male and female rat primary hepatocytes. As shown in Fig. 5B, both male and female hepatocytes rapidly form tazarotenic acid from tazarotene, with the reaction being essentially complete by $<20$ minutes. Thus, tazarotene was rapidly metabolized by esterase whose expression was not different between the sexes.

In summary, sex-different metabolism was shown for 6 of the 11 drugs predicted to have sex-different metabolism based on relative transcript levels of P450 genes. Of the five drugs for which sex-different metabolism could not be shown, three (irinotecan, phenytoin, and doxorubicin) were too slowly metabolized during the 2-hour incubation period in the hepatocyte system to accurately measure the half-life, and one (tazarotene) was rapidly metabolized by an enzyme whose gene expression was not sexually dimorphic. The remaining drug, pravastatin, failed to show the predicted sexually dimorphic metabolism, although a relatively large, but not statistically significant, sex difference was observed. Thus, excluding the four drugs that were too slowly or rapidly metabolized, six of seven drugs $(86 \%)$ were shown to have sexually dimorphic metabolism as predicted by our analysis of gene expression data.
Cytotoxicity of Drugs in Primary Rat Hepatocytes. Of the 41 drugs predicted to have sexually dimorphic metabolism based on the sex difference in expression of P450 mRNAs, 33 (Table 4) were chosen for cytotoxicity evaluation based on solubility in DMSO and availability. Three indicators of cytotoxicity were tested: Caspase 3/7 activity (indicator of apoptosis), $\mathrm{LDH}$ release from cells (indicator of necrosis), and cellular ATP concentration (indicator of energy dysregulation). An initial test on primary hepatocytes from one male and one female rat showed no toxicity of 14 drugs (amlodipine, buspirone, cetirizine,
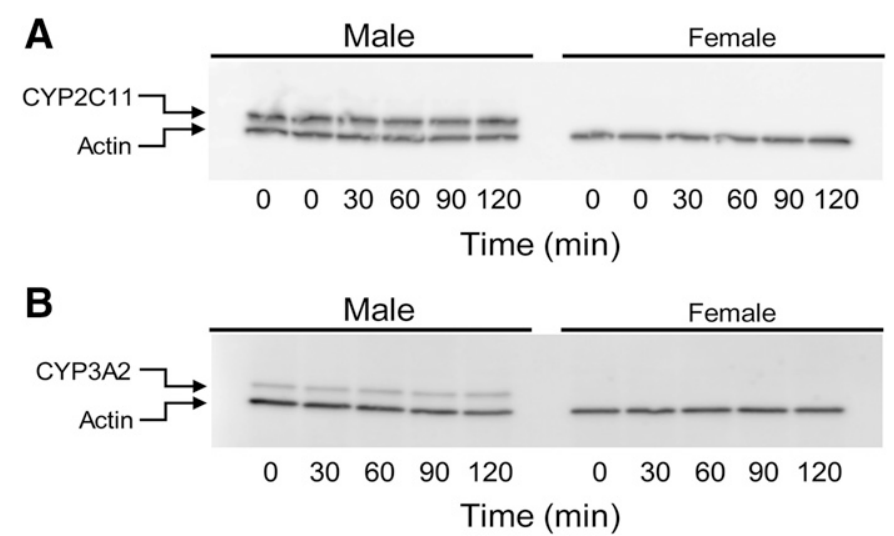

Fig. 3. Western blot analysis of $\mathrm{P} 450$ proteins in untreated suspension cultures of primary hepatocytes derived from male and female F344 rats. (A) CYP2C11 and (B) CYP3A2, along with a control protein, actin, were measured at $0,30,60,90$, and 120 minutes of culture. $\mathrm{P} 450$ protein levels were measured in hepatocytes from three males and three females, and representative blots are shown. Replicate of the sample at time 0 are shown in (A). 
A
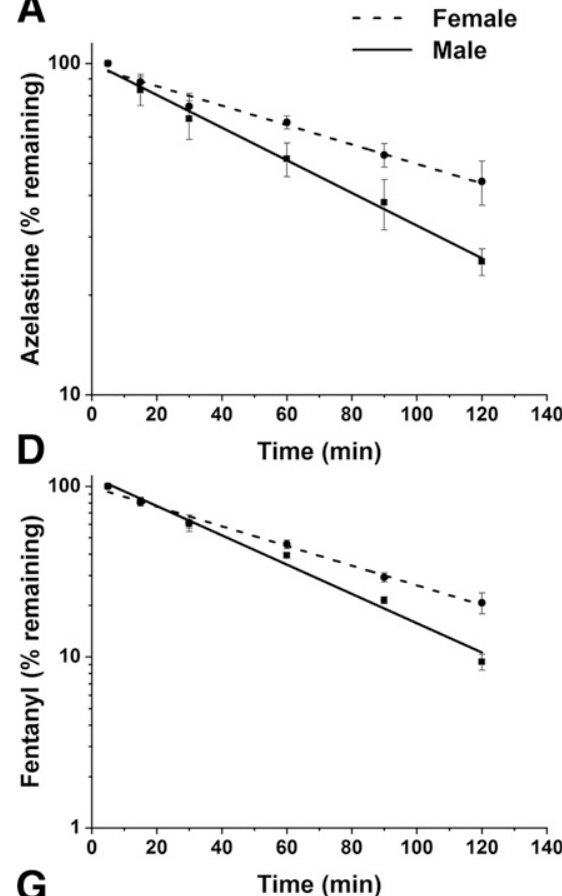

G

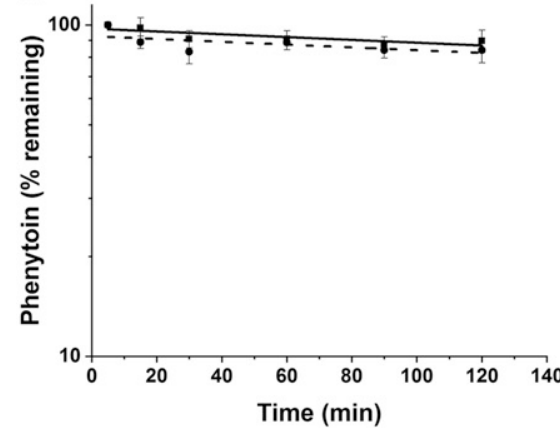

B

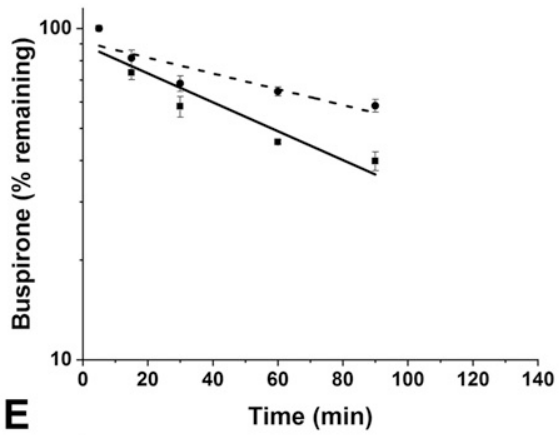

E
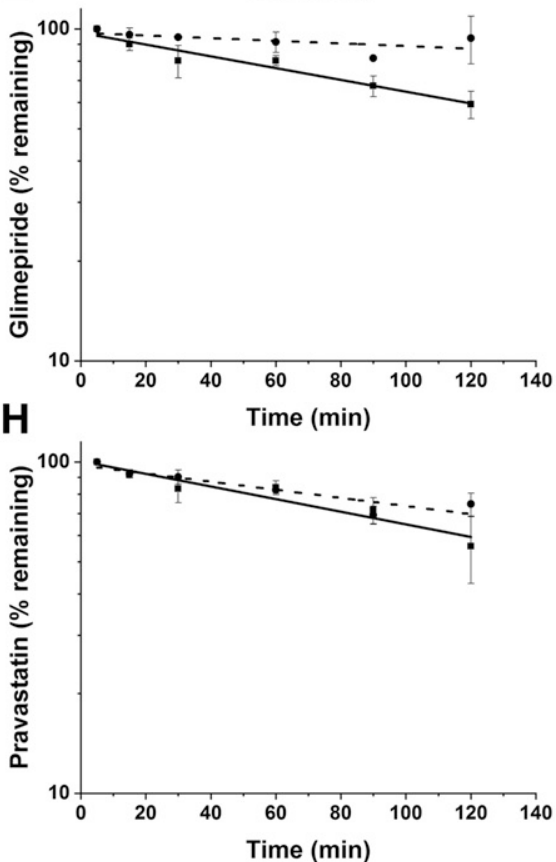

C
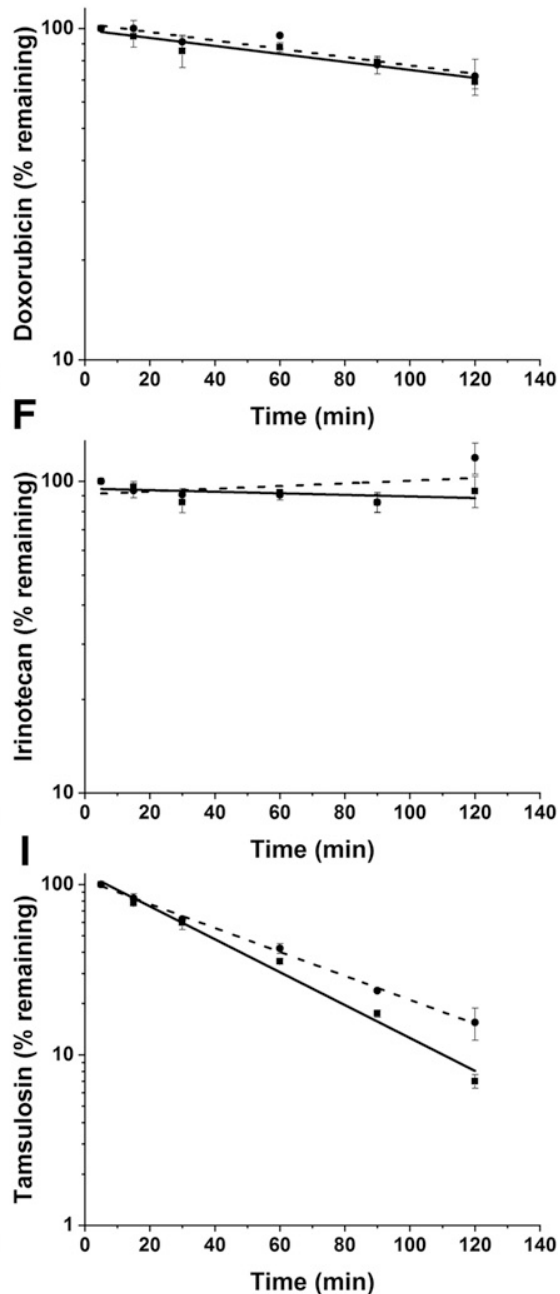

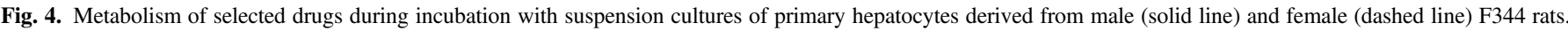

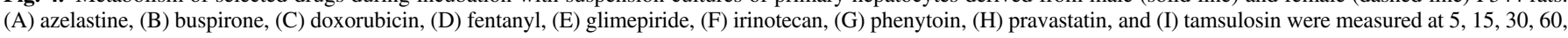

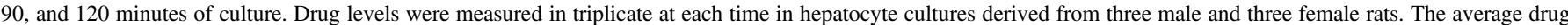

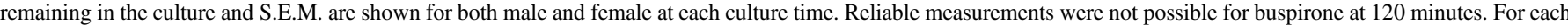

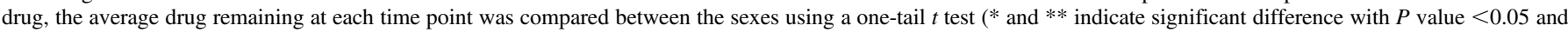

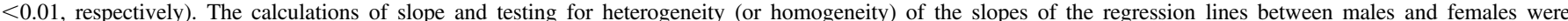

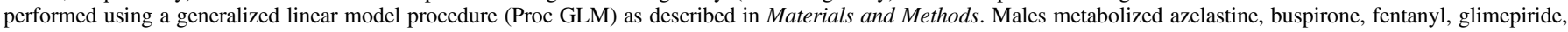
and tamsulosin significantly more rapidly than females $(P<0.01)$.

digoxin, ebastine, fentanyl, flunisolide, levobupivacaine, lidocaine, loratadine, medroxyprogesterone, mometasone, norethindrone, and oxybutynin) in any of the assays at doses ranging from $C_{\max }$ to 30 times $C_{\max }$. The remaining 19 drugs (Table 4) were tested in the three assays using primary hepatocytes from three male and three female rats. Only two drugs showed significant toxicity in any assay at doses ranging from $C_{\max }$ to 30 times $C_{\max }$. Doxorubicin and terfenadine were both toxic in the LDH assay (Fig. 7). The decrease in the measured LDH leakage at higher concentrations of doxorubicin is likely because the released LDH is degraded over time. Doxorubicin was only toxic to primary hepatocytes from male rats at the doses tested, whereas terfenadine was toxic to primary hepatocytes from both male and female rats. Hepatocytes from female rats were more sensitive to terfenadine, however, than those from male rats.

\section{Discussion}

Transcriptomic profiling has become a routine, relatively inexpensive, and straightforward technique to gain a comprehensive picture of gene expression in tissues under a variety of conditions, including disease and aging. From such studies, insights have been gained as to mechanisms of disease, development of biomarkers, and possible treatments and interventions (van 't Veer et al., 2002; Karczewski and Snyder, 2018). In addition, transcript profiling of tissues has revealed sex differences in gene expression, including genes coding for DMETs, in both model organisms (Yu et al., 2014) and humans (Yang et al., 2012; Tukiainen et al., 2017). On one hand, transcriptomics has the advantage of being high throughput and relatively inexpensive and providing global insight into differential expression of genes (either due to inherent difference or in response to external agents) resulting in the elucidation of different pathways (and mechanism) involved. On the other hand, just examining the transcriptomics profiling alone may not provide a complete picture of the full mechanism, as the translational products of transcripts, the proteins, are the ones performing the major tasks. Furthermore, there are various other processes, such as alternative splicing, protein modifications (e.g., glycosylation and folding), phosphorylation status, and translocation to site of activity, that play a major role in protein and 
A
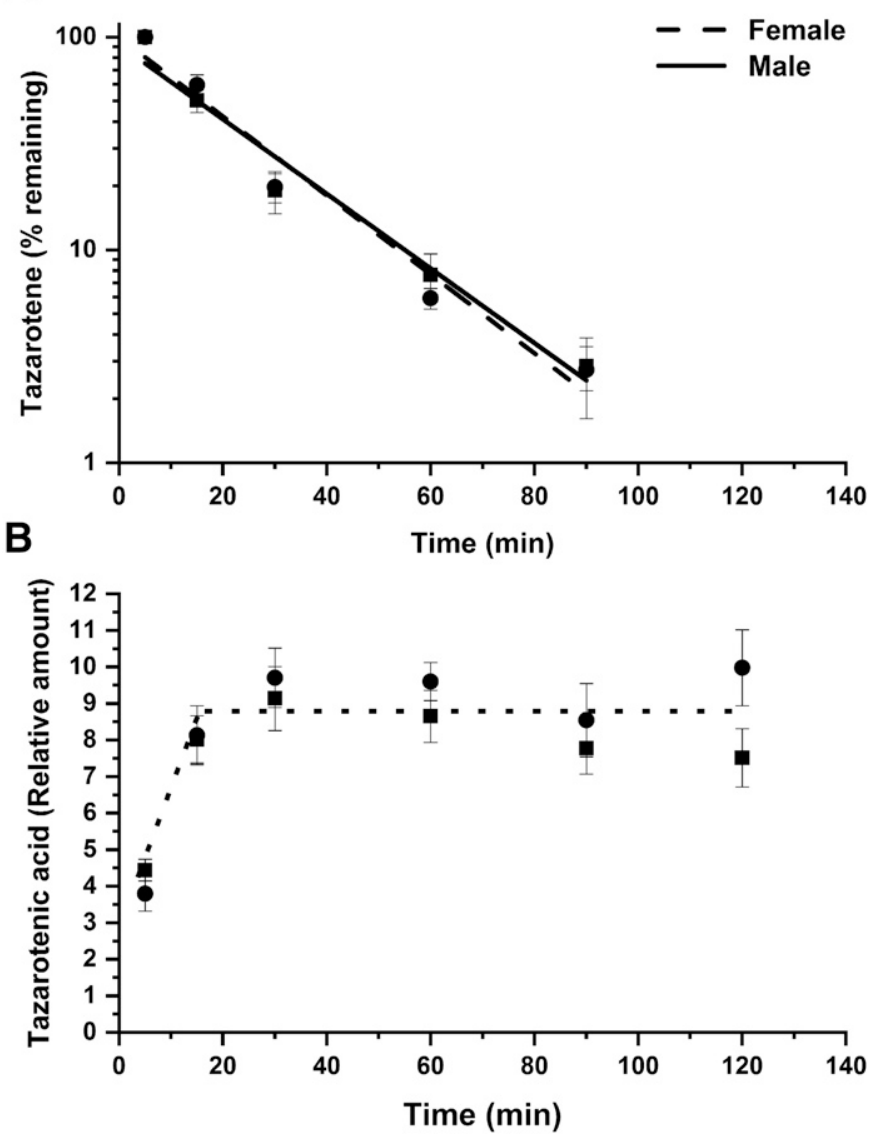

Fig. 5. Metabolism of tazarotene and formation of tazarotenic acid from tazarotene in suspension cultures of primary rat hepatocytes derived from male (solid line) and female (dashed line) F344 rats. Drug levels were measured in triplicate at each time $(5,15,30,60,90$, and 120 minutes of culture) in hepatocyte cultures derived from three male and three female rats. The average relative drug amount in the culture and S.E.M. are shown for both male (filled square) and female (filled circle) at each culture time. The calculations of slope and testing for heterogeneity (or homogeneity) of the slopes of the regression lines between males and females were performed using a generalized linear model procedure (Proc GLM) as described in Materials and Methods. (A) No significant difference between males and females was seen in the metabolism of tazarotene. (B) No significant difference between males and females was seen in the metabolism of tazarotene to tazarotenic acid. Dotted line indicates the average of male and female relative tazarotenic acid levels.

enzyme activity. All the aforementioned processes have the potential for sex- and/or age-related differences. Predicting biologic outcomes is not easy because of involvement of various dynamic processes within the body, and any prediction tool or method has limited applicability. Keeping the merits and limitations of transcriptomics in mind, the present study was designed to determine if sex-different expression of genes coding for DMETs alone could be used to predict sex-different drug metabolism of certain drugs and, thus, provide a new tool for protecting susceptible subpopulations from possible adverse drug events.

Approximately $10 \%$ (29) of the 298 genes that encode DMETs were found to be expressed at significantly different levels in the livers of adult male and female F344 rats, suggesting possible differences in how drugs are metabolized by males and females. Twelve of these genes were more highly expressed in females, and 17 were more highly expressed in males. Collectively, the enzymes encoded by these sexually dimorphic genes are involved in the metabolism of more than 600 drugs (Supplemental Table 2), indicating the importance of understanding the possible sex effects on drug metabolism.

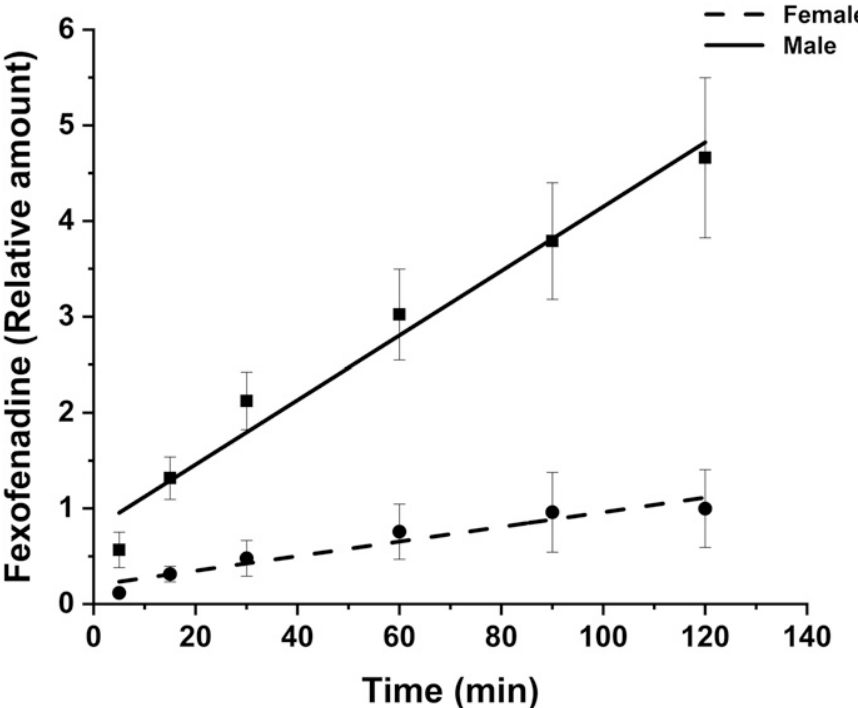

Fig. 6. Formation of fexofenadine from terfenadine in suspension cultures of primary rat hepatocytes derived from male (solid line) and female (dashed line) F344 rats. Fexofenadine levels were measured in triplicate at each time in hepatocyte cultures derived from three male and three female rats. The average drug remaining in the culture and S.E.M. are shown for both male (filled square) and female (filled circle) at each culture time. The average drug remaining at each time point was compared between the sexes using a one-tail $t$ test $(*$ and $* *$ indicate significant difference with $P$ value $<0.05$ and $<0.01$, respectively). The calculations of slope and testing for heterogeneity (or homogeneity) of the slopes of the regression lines between males and females were performed using a generalized linear model procedure (Proc GLM) as described in Materials and Methods. Males metabolized terfenadine to fexofenadine significantly more rapidly than females $(P<0.0001)$.

Based on the data from PharmaPendium, 41 drugs were found to be metabolized by only one or two P450s, and these were considered candidate drugs to determine whether different levels of the mRNAs that code for their drug metabolizing enzymes translated into different drug metabolism rates. Eleven drugs were chosen that represented several drug classes and were metabolized by each of the sex-biased P450s. Although the P450-drug association for these 11 drugs was initially obtained from PharmaPendium, a survey of literature reports allowed us to confirm such association, namely, azelastine (Imai et al., 1999), buspirone (Zhu et al., 2005), doxorubicin (Kivistö et al., 1995), fentanyl (Lötsch et al., 2013), glimepiride (Suzuki et al., 2006; Yang et al., 2018), irinotecan (Mathijssen et al., 2001), phenytoin (Franco and Perucca, 2015), pravastatin (Williams and Feely, 2002), tamsulosin (FrancoSalinas et al., 2010), tazarotene (Attar et al., 2003), and terfenadine (Ling et al., 1995), were mainly metabolized by the P450 as indicated in the PharmaPendium. The metabolism of these drugs was evaluated in primary hepatocytes derived from the livers of adult male and female F344 rats.

Of the 11 drugs tested in hepatocytes, three (doxorubicin, irinotecan, and phenytoin) were not substantially metabolized, and thus a determination of sex-different metabolism could not be reached. A fourth drug, tazarotene, was rapidly metabolized in both male and female hepatocytes. A literature search showed that this prodrug was metabolized by esterases to the active drug, tazarotenic acid (Madhu et al., 1997). Measurement of this reaction in the male and female hepatocytes showed that the esterases were not sexually dimorphic. Of the remaining seven drugs, six (83\%), namely, azelastine, buspirone, fentanyl, glimepiride, tamsulosin, and terfenadine, were found to be metabolized differently by male and female hepatocytes as predicted by the gene expression profiles and match the drug-P450 association found in literature for humans (Ling et al., 1995; Imai et al., 1999; Zhu et al., 2005; Suzuki et al., 2006; Franco-Salinas et al., 2010; Lötsch et al., 
TABLE 5

Half-lives of seven drugs in male and female primary rat hepatocytes

\begin{tabular}{lccc}
\hline Drug & Rat sex & $t_{1 / 2}$ & $P$ value $^{a}$ \\
\hline \multirow{4}{*}{ Azelastine } & & mean \pm S.D., min & \\
& Male & $61 \pm 7$ & 0.042 \\
Buspirone & Female & $107 \pm 34$ & \\
& Male & $70 \pm 11$ & 0.023 \\
Fentanyl & Female & $132 \pm 36$ & 0.002 \\
& Male & $35 \pm 2$ & 0.027 \\
Glimepiride & Female & $52 \pm 5$ & 0.018 \\
& Male & $194 \pm 74$ & 0.481 \\
Tamsulosin & Female & $329 \pm 45$ & \\
& Male & $31 \pm 1$ & \\
Pravastatin & Female & $43 \pm 6$ & 0.281 \\
& Male & $263 \pm 265$ & \\
Tazarotene & Female & $255 \pm 77$ & \\
& Male & $17 \pm 2$ & \\
& Female & $16 \pm 2$ & \\
& & &
\end{tabular}

${ }^{a}$ Comparison of drug half-life in males and females.

2013). The seventh drug, pravastatin, failed to show the predicted sexually dimorphic metabolism, although a relatively large, but not statistically significant, sex difference was observed. This may be explained in part by insignificant metabolism of pravastatin by CYP3A subfamily, which metabolizes most of the statin drugs (Williams and Feely, 2002). Thus, simple measures of gene expression are sufficient to give a strong indication of sex-different drug metabolism, and further evaluation of such drugs may benefit from increased attention to possible sex differences in efficacy and adverse effects.

Thirty-three drugs were evaluated for cytotoxicity and were found to be generally nontoxic under the conditions used. Only one drug with sex-different metabolism, terfenadine, was found to be cytotoxic in primary rat hepatocytes. Terfenadine has been shown to be cytotoxic to primary hepatocytes of both rats and humans (Jurima-Romet et al., 1996), and the results presented here show less toxicity in hepatocytes from female rats, in which metabolism of terfenadine was faster, than in hepatocytes from male rats. Thus, in at least one case, sex-different drug metabolism resulted in sex-different toxicity.

Despite the high ability to predict sex-different drug metabolism based on DMET transcript profiles, four drugs did not meet our expectations of sex-different metabolism because of incomplete knowledge of their basic metabolism. This was due to our efforts to standardize the analysis and hypothesis testing by relying exclusively on the knowledge base captured in PharmaPendium for making our predictions. We also, purposely, did not examine drug half-life information contained in the data base to prevent unintentional bias. It is possible that examination of the half-life information in PharmaPendium would have alerted us to the long half-lives of doxorubicin, irinotecan, and phenytoin, and we could have eliminated them from our hypothesis testing in the 2-hour incubation with primary rat hepatocytes. A retrospective search of half-life information in the data base showed doxorubicin to have the longest half-life (20-50 hours) among the 11 drugs. Moreover, a literature survey also indicated that doxorubicin is primarily metabolized into doxorubicinol by aldoketoreductases and that the CYP3A subfamily may play a role in doxorubicin metabolism (Kivistö et al., 1995). However, the half-lives of irinotecan and phenytoin overlapped with some of the remaining eight drugs so that we would not have excluded them based on this new information. Importantly, the half-life information in PharmaPendium is derived mainly from clinical studies, so a cross-species extrapolation may not always be accurate (Turpeinen et al., 2007). An in vivo pharmacokinetic study utilizing male and female F344 rats may allow the evaluation of metabolism of drugs with relatively long half-lives and allow the
A

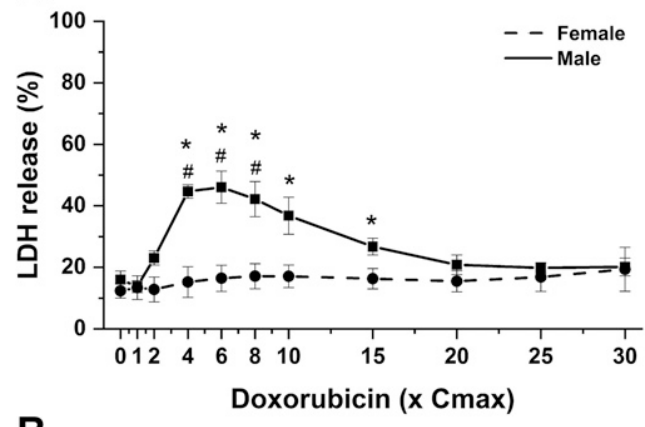

B

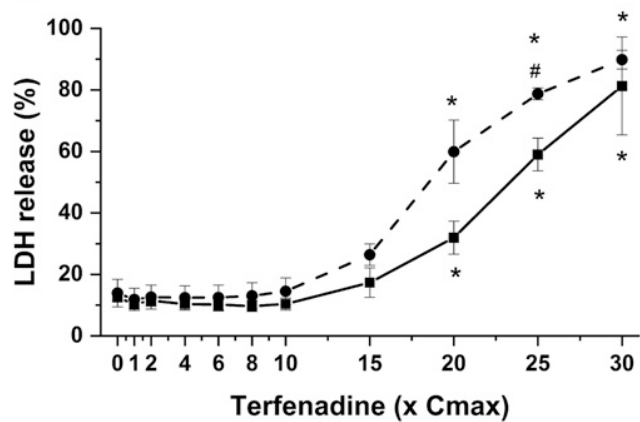

Fig. 7. Cytotoxicity of doxorubicin (A) and terfenadine (B). LDH release from hepatocytes was measured 24 hours after addition of the tested drugs ( 1 times to 30 times $C_{\max } ; C_{\max }$ is $110 \mathrm{ng} / \mathrm{ml}$ for doxorubicin and $229 \mathrm{ng} / \mathrm{ml}$ for terfenadine; Supplemental Table 3 ) and cytotoxicity expressed as the percentage of total cellular LDH. Significant cytotoxicity compared with untreated control cultures is indicated by $*(P<0.05)$. Significant difference in cytotoxicity between male and female hepatocytes at corresponding times is indicated by \# $(P<0.05)$. Shown are the average measurements and S.E.M. for hepatocytes derived from three male (solid line) and three female (dashed line) F344 rats.

hypothesis testing of drugs with long half-lives. Tazarotene was rapidly metabolized to tazarotenic acid by esterase by both male and female hepatocytes and without a sex difference. PharmaPendium did not contain information on the metabolism of tazarotene by esterase but listed tazarotene as an enzyme substrate of CYP2C8 (rat ortholog is Cyp2c7). Tazarotene is actually metabolized to tazarotenic acid by esterases and then tazarotenic acid is metabolized into a sulfoxide metabolite by CYP2C8 and flavin-containing monooxygenases (Attar et al., 2003). Thus, although PharmaPendium contains much valuable regulatory information from drug approval packages, in future studies and applications of this method, improved accuracy may be obtained by using as much existing information as possible from all available sources.

These data suggest that possible sex differences in drug metabolism in the preclinical rat model during drug development may be computationally identified using existing P450 gene expression profiles combined with the accruing knowledge of the candidate drug metabolism pathway. Any sex difference can then be confirmed by relatively high throughput cell metabolism studies using primary hepatocytes derived from male and female rats. Extension of this computational method to other classes of DMETs whose mRNA expression was sex different, such as other phase 1 metabolizers, phase 2 metabolizers, and drug transporters (Tables 2 and 3), would allow a more complete evaluation of sex-different metabolism. In addition, this method may be applicable to evaluation of other susceptible subpopulations such as children and the elderly. Children (Joseph et al., 2015; Germovsek et al., 2019) and the elderly (Ridda et al., 2008; Herrera et al., 2010; Cho et al., 2011) are frequently not included in clinical trials, so the direct information needed to make benefit-risk assessments is often simply 
not available for these populations. Extrapolations are then made from results of studies performed in predominantly middle-aged adult populations, even though changes in DMETs during development are known to occur (Hines, 2008). This may lead to vulnerable patient populations being exposed to possibly ineffective therapies and unknown risks of adverse events (Hilmer and Gazarian, 2008). In the absence of direct clinical trial assessments of drug safety and efficacy in patients at the extremes of age, preclinical studies are often used to inform decision making (www.fda.gov/downloads/drugs/ guidancecomplianceregulatoryinformation/guidances/ucm079247). Therefore, alternative methods are needed to identify potential drug safety issues in susceptible populations. Coupling drug metabolizing enzyme information with gene expression profiles of preclinical models during the life span may allow better assessment of potential susceptibilities to adverse events.

One caveat of the present study is that drug transporters were not investigated. The two drugs tested in this study, pravastatin and glimepiride, are well established substrates for organic anion transporting polypeptide transporters. However, the liver gene expressions of these transporters were not significantly different between male and female rats. Thus, the sex-biased difference in metabolism for these two drugs observed here is less likely to be caused by their transporters, although gene expression levels may not necessarily reflect the function levels of the corresponding proteins. Nevertheless, some genes for the ATP-binding cassette and the solute carrier protein transporter families were indeed found to be differentially expressed between male and female rats (Tables 2 and 3). Further studies are needed to elucidate the role of these transporters in sex-biased drug metabolism and toxicity.

Perhaps the largest benefit to drug evaluation would be to use humanderived gene expression data and drug metabolism knowledge, since P450 enzyme activities are known to differ between humans and experimental animal species (Turpeinen et al., 2007). Currently, large human data sets of gene expression across multiple normal and diseased tissues, including the liver, of both sexes through the life span are not available. As these become available through efforts such as the Genotype-Tissue Expression Consortium (GTEx Consortium, 2015), direct application of this method to humans will allow assessment of sex and age differences in drug metabolism that may lead to differences in drug efficacy or adverse events. The ability to identify subpopulations, based upon sex or age, with susceptibilities to adverse events will better inform the regulatory decisions that are made with regard to drugs and other FDA-regulated products.

\section{Acknowledgments}

We thank Dr. Jun Zhang for her help with the cytotoxicity assays and Carrie Moland for shipping samples. We also thank Dr. Amy Inselman for valuable suggestions on the manuscript.

\section{Authorship Contributions}

Participated in research design: Fuscoe, Vijay, Hanig, Beger, Shi.

Conducted experiments: Han, Ren, Greenhaw, Pence, Shi.

Performed data analysis: Fuscoe, Vijay, Han, Shi.

Wrote or contributed to the writing of the manuscript: Fuscoe, Vijay, Han, Shi.

\section{References}

Arrowsmith J (2011) Trial watch: phase III and submission failures: 2007-2010. Nat Rev Drug Discov 10:87.

Attar M, Dong D, Ling KH, and Tang-Liu DD (2003) Cytochrome P450 2C8 and flavin-containing monooxygenases are involved in the metabolism of tazarotenic acid in humans. Drug Metab Dispos 31:476-481.

Beery AK and Zucker I (2011) Sex bias in neuroscience and biomedical research. Neurosci Biobehav Rev 35:565-572.

Cho S, Lau SW, Tandon V, Kumi K, Pfuma E, and Abernethy DR (2011) Geriatric drug evaluation: where are we now and where should we be in the future? Arch Intern Med 171 937-940.
Clayton JA and Collins FS (2014) Policy: NIH to balance sex in cell and animal studies. Nature 509:282-283.

Fang H, Harris SC, Su Z, Chen M, Qian F, Shi L, Perkins R, and Tong W (2009) ArrayTrack: an FDA and public genomic tool. Methods Mol Biol 563:379-398.

Franco V and Perucca E (2015) CYP2C9 polymorphisms and phenytoin metabolism: implications for adverse effects. Expert Opin Drug Metab Toxicol 11:1269-1279.

Franco-Salinas G, de la Rosette JJ, and Michel MC (2010) Pharmacokinetics and pharmacodynamics of tamsulosin in its modified-release and oral controlled absorption system formulations. Clin Pharmacokinet 49:177-188.

Germovsek E, Barker CIS, Sharland M, and Standing JF (2019) Pharmacokineticpharmacodynamic modeling in pediatric drug development, and the importance of standardized scaling of clearance. Clin Pharmacokinet 58:39-52.

Greenblatt DJ, Harmatz JS, von Moltke LL, Wright CE, and Shader RI (2004) Age and gender effects on the pharmacokinetics and pharmacodynamics of triazolam, a cytochrome P450 3A substrate. Clin Pharmacol Ther 76:467-479.

GTEx Consortium (2015) Human genomics. The Genotype-Tissue Expression (GTEx) pilot analysis: multitissue gene regulation in humans. Science 348:648-660.

Herrera AP, Snipes SA, King DW, Torres-Vigil I, Goldberg DS, and Weinberg AD (2010) Disparate inclusion of older adults in clinical trials: priorities and opportunities for policy and practice change. Am J Public Health 100 (Suppl 1):S105-S112.

Hilmer SN and Gazarian M (2008) Clinical pharmacology in special populations: the extremes of age. Expert Rev Clin Pharmacol 1:467-469.

Hines RN (2008) The ontogeny of drug metabolism enzymes and implications for adverse drug events. Pharmacol Ther 118:250-267.

Imai T, Taketani M, Suzu T, Kusube K, and Otagiri M (1999) In vitro identification of the human cytochrome P-450 enzymes involved in the N-demethylation of azelastine. Drug Metab Dispos 27:942-946.

Institute of Medicine (2010) Women's Health Research: Progress, Pitfalls, and Promise, National Academies Press, Washington, DC.

Joseph PD, Craig JC, and Caldwell PH (2015) Clinical trials in children. Br J Clin Pharmacol 79:357-369.

Jurima-Romet M, Huang HS, Beck DJ, and Li AP (1996) Evaluation of drug interactions in intact hepatocytes: inhibitors of terfenadine metabolism. Toxicol In Vitro 10:655-663.

Karczewski KJ and Snyder MP (2018) Integrative omics for health and disease. Nat Rev Genet 19. 299-310.

Kivistö KT, Kroemer HK, and Eichelbaum M (1995) The role of human cytochrome P450 enzymes in the metabolism of anticancer agents: implications for drug interactions. Br J Clin Pharmacol 40:523-530.

Kwekel JC, Desai VG, Moland CL, Branham WS, and Fuscoe JC (2010) Age and sex dependent changes in liver gene expression during the life cycle of the rat. BMC Genomics 11:675.

Kwekel JC, Desai VG, Moland CL, Vijay V, and Fuscoe JC (2013a) Life cycle analysis of kidney gene expression in male F344 rats. PLoS One 8: 75305.

Kwekel JC, Desai VG, Moland CL, Vijay V, and Fuscoe JC (2013b) Sex differences in kidney gene expression during the life cycle of F344 rats. Biol Sex Differ 4:14

Laemmli UK (1970) Cleavage of structural proteins during the assembly of the head of bacteriophage T4. Nature 227:680-685.

Ling KH, Leeson GA, Burmaster SD, Hook RH, Reith MK, and Cheng LK (1995) Metabolism of terfenadine associated with CYP3A(4) activity in human hepatic microsomes. Drug Metab Dispos 23:631-636.

Livak KJ and Schmittgen TD (2001) Analysis of relative gene expression data using real-time quantitative PCR and the 2(-Delta Delta C(T)) method. Methods 25:402-408.

Lötsch J, Walter C, Parnham MJ, Oertel BG, and Geisslinger G (2013) Pharmacokinetics of nonintravenous formulations of fentanyl. Clin Pharmacokinet 52:23-36.

Madhu C, Duff S, Baumgarten V, Rix P, Small D, and Tang-Liu D (1997) Metabolic deesterification of tazarotene in human blood and rat and human liver microsomes. J Pharm Sci 86: 972-974.

Mathijssen RH, van Alphen RJ, Verweij J, Loos WJ, Nooter K, Stoter G, and Sparreboom A (2001) Clinical pharmacokinetics and metabolism of irinotecan (CPT-11). Clin Cancer Res 7:2182-2194.

McIntyre IM (2014) Liver and peripheral blood concentration ratio (L/P) as a marker of postmortem drug redistribution: a literature review. Forensic Sci Med Pathol 10:91-96.

Moore TJ, Cohen MR, and Furberg CD (2007) Serious adverse drug events reported to the Food and Drug Administration, 1998-2005. Arch Intern Med 167:1752-1759.

Paech F, Abegg VF, Duthaler U, Terracciano L, Bouitbir J, and Krähenbühl S (2018) Sunitinib induces hepatocyte mitochondrial damage and apoptosis in mice. Toxicology 409:13-23.

Ridda I, Lindley R, and MacIntyre RC (2008) The challenges of clinical trials in the exclusion zone: the case of the frail elderly. Australas J Ageing 27:61-66.

Shi Q, Yang X, Greenhaw J, and Salminen WF (2011) Hepatic cytochrome P450s attenuate the cytotoxicity induced by leflunomide and its active metabolite A77 1726 in primary cultured rat hepatocytes. Toxicol Sci 122:579-586.

Soldin OP, Chung SH, and Mattison DR (2011) Sex differences in drug disposition. J Biomed Biotechnol 2011:187103.

Soldin OP and Mattison DR (2009) Sex differences in pharmacokinetics and pharmacodynamics. Clin Pharmacokinet 48:143-157.

Suzuki K, Yanagawa T, Shibasaki T, Kaniwa N, Hasegawa R, and Tohkin M (2006) Effect of CYP2C9 genetic polymorphisms on the efficacy and pharmacokinetics of glimepiride in subjects with type 2 diabetes. Diabetes Res Clin Pract 72:148-154.

Tong W, Cao X, Harris S, Sun H, Fang H, Fuscoe J, Harris A, Hong H, Xie Q, Perkins R, et al (2003) ArrayTrack--supporting toxicogenomic research at the U.S. Food and Drug Administration National Center for Toxicological Research. Environ Health Perspect 111:1819-1826.

Tukiainen T, Villani AC, Yen A, Rivas MA, Marshall JL, Satija R, Aguirre M, Gauthier L, Fleharty M, Kirby A, et al.; GTEx Consortium; Laboratory, Data Analysis \& Coordinating Center (LDACC)—Analysis Working Group; Statistical Methods groupsAnalysis Working Group; Enhancing GTEx (eGTEx) groups; NIH Common Fund; NIH/ NCI; NIH/NHGRI; NIH/NIMH; NIH/NIDA; Biospecimen Collection Source SiteNDRI; Biospecimen Collection Source Site-RPCI; Biospecimen Core ResourceVARI; Brain Bank Repository-University of Miami Brain Endowment Bank; Leidos Biomedical-Project Management; ELSI Study; Genome Browser Data Integration \&Visualization-EBI; Genome Browser Data Integration \&Visualization-UCSC Genomics Institute, University of California Santa Cruz (2017) Landscape of X chromosome 
inactivation across human tissues [published correction appears in Nature 555 274:2018]. Nature 550:244-248.

Turpeinen M, Ghiciuc C, Opritoui M, Tursas L, Pelkonen O, and Pasanen M (2007) Predictive value of animal models for human cytochrome P450 (CYP)-mediated metabolism: a comparative study in vitro. Xenobiotica 37:1367-1377.

van 't Veer LJ, Dai H, van de Vijver MJ, He YD, Hart AA, Mao M, Peterse HL, van der Kooy K, Marton MJ, Witteveen AT, et al. (2002) Gene expression profiling predicts clinical outcome of breast cancer. Nature 415:530-536.

Venuto CS, Markatou M, Woolwine-Cunningham Y, Furlage R, Ocque AJ, DiFrancesco R, Dumas EO, Wallace PK, Morse GD, and Talal AH (2017) Paritaprevir and ritonavir liver concentrations in rats as assessed by different liver sampling techniques. Antimicrob Agents Chemother 61:e2283-16.

Waxman DJ and Holloway MG (2009) Sex differences in the expression of hepatic drug metabolizing enzymes. Mol Pharmacol 76:215-228.

Weng Z, Luo Y, Yang X, Greenhaw JJ, Li H, Xie L, Mattes WB, and Shi Q (2015) Regorafenib impairs mitochondrial functions, activates AMP-activated protein kinase, induces autophagy, and causes rat hepatocyte necrosis. Toxicology 327:10-21.

Williams D and Feely J (2002) Pharmacokinetic-pharmacodynamic drug interactions with HMGCoA reductase inhibitors. Clin Pharmacokinet 41:343-370.

Yang F, Xiong X, Liu Y, Zhang H, Huang S, Xiong Y, Hu X, and Xia C (2018) CYP2C9 and OATP1B1 genetic polymorphisms affect the metabolism and transport of glimepiride and gliclazide. Sci Rep 8:10994.

Yang L, Li Y, Hong H, Chang CW, Guo LW, Lyn-Cook B, Shi L, and Ning B (2012) Sex differences in the expression of drug-metabolizing and transporter genes in human liver. J Drug Metab Toxicol 3:1000119.
Yu Y, Fuscoe JC, Zhao C, Guo C, Jia M, Qing T, Bannon DI, Lancashire L, Bao W, Du T, et al. (2014) A rat RNA-seq transcriptomic BodyMap across 11 organs and 4 developmental stages. Nat Commun 5:3230.

Zanger UM and Schwab M (2013) Cytochrome P450 enzymes in drug metabolism: regulation of gene expression, enzyme activities, and impact of genetic variation. Pharmacol Ther 138: 103-141.

Zhang J, Ren L, Yang X, White M, Greenhaw J, Harris T, Wu Q, Bryant M, Papoian T, Mattes W, et al. (2018) Cytotoxicity of 34 FDA approved small-molecule kinase inhibitors in primary rat and human hepatocytes. Toxicol Lett 291:138-148.

Zhu M, Zhao W, Jimenez H, Zhang D, Yeola S, Dai R, Vachharajani N, and Mitroka J (2005) Cytochrome P450 3A-mediated metabolism of buspirone in human liver microsomes. Drug Metab Dispos 33:500-507.

Zucker I and Beery AK (2010) Males still dominate animal studies. Nature 465:690.

Address correspondence to: Dr. James C. Fuscoe, Division of Systems Biology, National Center for Toxicological Research, US Food and Drug Administration, 3900 NCTR Rd., Jefferson, AR 72079. E-mail: jfuscoe@gmail.com; or Dr. Vikrant Vijay, Division of Systems Biology, National Center for Toxicological Research, US Food and Drug Administration, 3900 NCTR Rd., Jefferson, AR 72079. E-mail: vikrant.vijay@fda.hhs.gov 